\title{
Is norethisterone a lifestyle drug? Results of database analysis
}

Judy Shakespeare, Elizabeth Neve, Karen Hodder

Norethisterone has several indications in gynaecology and primary care. At low dose ( $\leq 1 \mathrm{mg}$ a day) it can be use in combination with oestrogens either as a contraceptive or in hormone replacement therapy. At higher dose ( $\geq 5 \mathrm{mg}$ daily) it can be used for menorrhagia, to treat metropathia haemorrhagica, and to postpone menstruation. Norethisterone is not available in a formulation greater than $5 \mathrm{mg}$. Recent evidence has suggested that at conventional doses $(5-10 \mathrm{mg}$ /day) it is not effective for menorrhagia. ${ }^{12}$ In Oxfordshire we have been exploring prescribing for menorrhagia as part of implementing the Royal College of Obstetricians and Gynaecologists' recommendations for the initial management of menorrhagia in primary care. ${ }^{3}$

\section{Method and results}

We obtained electronic prescribing analysis and cost information on the number of prescriptions for norethisterone $5 \mathrm{mg}$ issued by Oxfordshire general practitioners between April 1995 and December 1998. We also obtained prescribing levels for general practitioners in England from February 1997 until January 1999. We conducted a computer literature search using the key Medical Subject Headings (MeSH) terms "norethindrone" (for Medline) and "norethisterone" (for Embase), "holidays," "periodicity," and "menstruation" in Medline 1966-March 1999, Embase 1980-1999/2001, and the Cochrane Library issue 31998.

The figure shows the prescribing levels for Oxfordshire and England (excluding Oxfordshire). Over the four years the baseline prescribing of norethisterone in Oxfordshire was about 600 items/month/ million population between October and April. Between November 1995 and November 1998, there was a marked decrease in prescribing, with a significant difference between these minimums $(\mathrm{P}<0.01)$. From April each year, the number of items prescribed rose rapidly

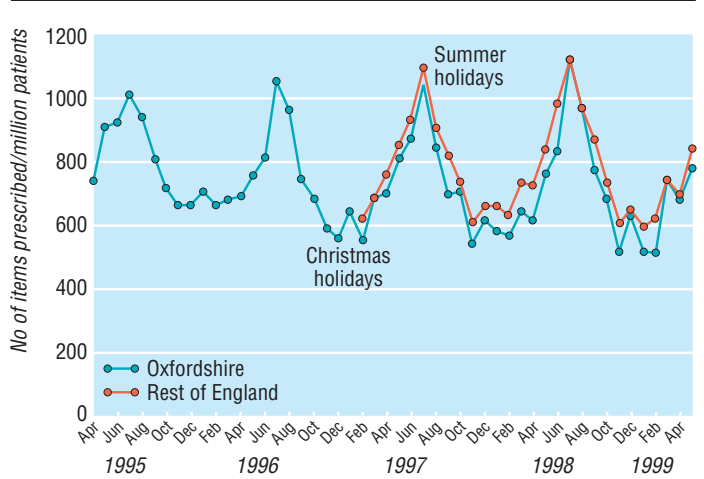

Prescribing patterns of norethisterone $5 \mathrm{mg}$ for general practitioners in Oxfordshire and the rest of England to a maximum in July of about 1100 items/month/ million population. There are sub-peaks in prescribing around the Christmas and new year period in each year. This prescribing pattern is the same as the English prescribing levels, which are available only for the past two years. In our literature search we found no other papers describing this phenomenon.

\section{Comment}

This seasonal variation in prescribing cannot be explained by metropathia haemorrhagica or menorrhagia. The significant reduction in the minimums of the prescribing values suggest that Oxfordshire general practitioners may have changed their prescribing for menorrhagia. It seems most likely that the seasonal peaks in prescribing were due to patients wishing to delay menstruation during holidays, particularly summer holidays. We have no information about whether this prescribing was doctor or patient generated, whether it was the same patients who requested prescriptions each year, or whether this generated extra workload in consultations or the prescriptions were obtained as repeats. Since this prescribing pattern for norethisterone was replicated in the national data, the seasonal variation cannot be due to the relatively affluent and well informed population in Oxfordshire (which is in band 2 of the Jarman score based area classification of deprivation, where band 1 represents the most affluent of seven bands in total) or to the large student population of Oxfordshire $(7.7 \%$ of the Oxfordshire population in the 1991 census, compared with the English average of $4.3 \%)$.

If this seasonal prescribing is to delay periods during holidays this would make norethisterone a "lifestyle drug"-that is, "a pharmaceutical product characterised as improving quality of life rather than alleviating or curing disease." ${ }^{\prime 4}$ Whether this lifestyle or convenience prescribing is appropriate for the NHS is open for debate. Fortunately, norethisterone is a cheap drug at $£ 7.20 / 100$ 5mg tablets ${ }^{5}$ (unlike sildenafil), has few side effects and most patients who take it are likely to be paying prescription costs.

Contributors: JS had the original idea for the paper, had prime responsibility for writing the manuscript, and is guarantor for the study. EN produced the original graphs that, in discussion with JS, provoked the study. KH did the statistical analysis and contributed to writing the manuscript.

Competing interests: None declared

1 Coulter A, Kelland J, Peto V, Rees M. Treating menorrhagia in primary care: an overview of drug trials and a survey of prescribing practice. Int J Technol Assess Health Care 1995;11:456-71.

2 Effective health care: No 9. The management of menorrhagia. York: NHS Centre for reviews and dissemination, 1995.

3 Roval College of Obstetricians and Gynaecologists. The initial management of menorrhagia:evidence-based clinical guidelines No 1. London: RCOG,1998.

4 Concise Oxford dictionary. 10th ed. Oxford: Oxford University Press, 1999.

5 Drug tariff. London: Stationery Office, 1999.

(Accepted 11 November 1999)
Summertown Health Centre, 160 Banbury Road, Oxford OX2 7BS Judy Shakespeare general practitioner

Oxfordshire Health Authority, Headington, Oxford OX3 9LG Elizabeth Neve prescribing analyst Karen Hodder senior information analyst

Correspondence to: J Shakespeare judy@shake-speare. demon.co.uk

BMJ 2000;320:291 